\title{
The father is dead! Long live the father!
}

[ B O OK RE VIE W ]

Lacan, Jacques (2013) The triumph of

religion. (Translated by Bruce Fink).

Cambridge: Polity Press.

ISBN 978-0-745-65989-3 hbk. Pages 92

\section{Derek Hook}

Department of Psychology

Duquesne University

Pittsburgh, PA

USA

Jacques Lacan, psychoanalytic proponent of the enigmatic interpretive gesture and baroque, over-stylized prose, is hardly known for making concessions to his audience. Nonetheless, he does offer something approximating an introduction to his famous notion "the unconscious is structured like a language" in the first of the two public lectures collected in the recently published The triumph of religion. "The central characteristic of the Freudian unconscious is to be translatable" (11) offers Lacan, adding, furthermore:

"What can be translated is technically called the signifier. It is an element that presents two dimensions: it is synchronically linked to a battery of other elements that can be substituted for it and it is available for diachronic use ... [in] the constitution of a signifying chain" (11-12).

Here then, sparsely described, are the two axes of linguistic functioning known as metaphor and metonymy. These are, respectively, related to the categorical substitution of one signifier for another ("the dimension of metaphor ... by which reality becomes infused with poetry" (13)), and the unfolding sequence of language as it is produced in succession ("the dimension ... [of] metonymy, which makes poetry of all realism" (13). These are the two basic operations 
of the unconscious, akin to Freud's condensation and displacement, which make "the unconscious ... by nature a discourse, assuming we allow ourselves to qualify a certain use of linguistic structures as discourse" (14). Psychoanalysis is thus concerned with

"everything that can be discerned regarding our behaviour as marked by the stamp of the signifier. This will bring ... [us] back to the very origin of psychoanalysis: the interpretation of dreams, slips of the tongue, and even jokes ... Look back at the texts by Freud on the themes I just mentioned - dreams, slips of the tongue and jokes - and you will never see desire being clearly articulated. Unconscious desire is what is meant by the one who or the thing that proffers unconscious discourse" (14-15).

This reassertion of the primacy of the signifier in the practice of psychoanalysis is then followed by a discussion of the role of the father in the unconscious. Given that Lacan is addressing the topic of religion, it is unsurprising that he speaks of Freud's (1939) Moses and monotheism, noting that the text is

"merely the endpoint and fulfilment of what began with the creation of the Oedipus complex and continues in a book that is so poorly understood ... [Totem and taboo]. In it you will see the figure that appears of the father concentrating upon itself love and hate; it is a magnified, magnificent figure, marked with a style of active and suffered cruelty" (22-23).

Lacan is here justifying his own theoretical contributions to psychoanalysis at the same moment he is paying homage to Freud, for in each of the above instances of Freud's work we see "meditations on the function, role, and figure of the Name-of-the-Father", which is likewise substantiated by "his entire ethical reference revolving around the properly Judeo-Christian tradition" (22). The role of religion, thus invoked, must thus be understood in relation to the function of the father within psychical and sociocultural life more generally. In opposition to the Kleinian (and subsequent object relations) emphasis on the mother, Lacan firmly re-establishes Freud's prioritization of the father. He makes the point explicitly: the paternal bond, founded as it is "on faith and law", ultimately "[takes] precedence over the maternal bond, which is founded on a manifest carnality" (27).

The reason for Lacan's "introductory" reiteration of the underlying principles of the Freudian unconscious in this context is now clear. The symbolic role played by the Name-of-the-Father is as crucial to his theorization of the unconscious as are the mechanisms of metonymy and metaphor. This much is evident when Lacan explores a little further, linking the prohibitive role of the father to desire and phobia alike. Freud's 
Totem and taboo (1912/1913), he avers, revolved around the function of the phobic object, and it is this function which guided Freud toward the function of the Father:

"This function constitutes a turning point between the preservation of desire in its omnipotence ... and the correlative principle of a prohibition that leads to the setting aside of this desire. The two principles wax and wane together even if their effects are different: the omnipotence of desire engenders fears of the defences that ensues in the subject, and prohibition drives the statement of desire away from the subject in order to transfer it to an Other, to the unconscious that knows nothing of what is propped up by its own enunciation" (24).

Behind the totem we find, again, the symbolic function of the father, a function that is never reducible to the actual empirical figure of the father. The allusion to the totem is instructive, and we come to realize how phobic and desiring effects are dynamically related: desire engenders fear and defences, and prohibition ensures that desires are transferred to the Other, made unconscious.

The complexity of this desire-prohibition relation - which is another way of understanding the effects of Name-of-the-Father, of the law instituted in the unconscious of the neurotic - is paradoxical in outcome. What Totem and taboo teaches us, says Lacan, is that the father prohibits desire effectively only because he is dead.

"This is the myth that Freud proposes to modern man, insofar as modern man is the one for whom God is dead ... Why does Freud adopt this paradoxical position? In order to explain that man's desire will be all the more threatening and thus that its prohibition will be all the more necessary and severe. God is dead, nothing is permitted anymore" (24-25).

The decline of the Oedipus complex, and presumably along with it, the apparent decline of the patriarchal figure of the powerful father, leaves us not with the freedom from prohibition that may have been longed for, but with an ever more durable law, and, worse yet, an identification with the punishing institution of the superego.

"We must examine in detail what this scrutiny of the function of the Father represents and introduce here the most precise distinctions, especially between what I have called the symbolic instance - the father who promulgates, who is the seat of the articulated law ... - around which the structure of neurosis is specified - and, on the other hand, something that contemporary analysis constantly neglects even though it is perceptible and alive everywhere for Freud: namely, the impact of the real father. Even when this impact is good or beneficial, it can, as a function of this structure, lead to ravaging and even maleficent effects" (Lacan, 2013: 25-26). 
We need to track then the effects not only of the symbolic father function ("seat of articulated law"), but also that of the real father (presumably, the castrating figure, the enjoying father, the father of a ravaging jouissance). Lacan's implication is clear: to be released from the autocratic form of paternal authority is not necessarily something we should welcome as it invariably means that we end up instituting something of this role under the auspices of our own self-policing superegos. The apparent demise of the cultural institution of the father in modernity is thus predicted by Freud's myth of the murder of the primal father: the father is dead, and the father lives on, stronger, more virulent, than ever before. 